\title{
Importancia del Criminal Compliance en la micro y pequeña empresa en el Perú
}

\section{Relevance of the Criminal Compliance within the Micro Businesses and Small Businesses in Perú}

\author{
Yasmina Riega-Virú* https://orcid.org/0000-0002-1725-9030 \\ Hubert Huamaní Chirinos** https://orcid.org/0000-0002-6833-1880 \\ http://dx.doi.org/10.21503/lex.v17i24.1816
}

* Abogada y magíster en Derecho Penal por la Universidad Nacional Federico Villarreal, licenciada en Educación en la especialidad de Filosofía y Ciencias Sociales por la Pontificia Universidad Católica del Perú, doctora en Derecho por la Universidad Alas Peruanas. Especialista en Compliance y Buen Gobierno Corporativo por la Universidad del Pacífico. Es docente investigador en la Universidad Privada del Norte. Docente en la Escuela de Posgrado de la Universidad Nacional Mayor de San Marcos y en la Universidad Privada San Juan Bautista. Dicta los cursos de Derecho Penal, Derecho Penal Comparado, Metodología de la Investigación Científica y Seminario de Tesis. Perú Correo electrónico: yasmina.riega@upn.edu.pe.

** Abogado y magíster en Derechos Humanos, Derecho Internacional Humanitario y Resolución de Conflictos por el Centro de Altos Estudios Nacionales, con estudios de maestría en Gestión Pública por la Universidad San Martín de Porres, master en Gerencia Pública por la Escuela de Negocios y Administración de Empresas EUCIM - España, árbitro de Derecho por la Cámara Peruana de Conciliación y Arbitraje CAPECA, especialista en Contrataciones Estatales por la Escuela de Negocios y Gobierno UTRIVIUM - OSCE. Es docente universitario en la Universidad Alas Peruanas y Universidad Privada Telesup. Dicta los cursos de Derecho Penal, Procesal Penal, Derecho Financiero, Derecho Económico, Política y Comercio Internacional. Perú. Correo electrónico: h_huamani_c@doc.uap.edu.

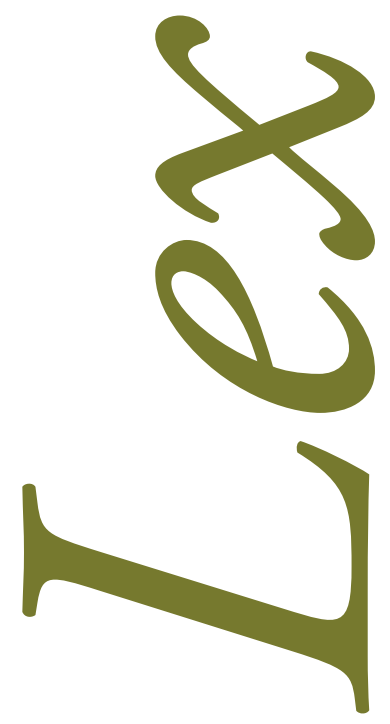




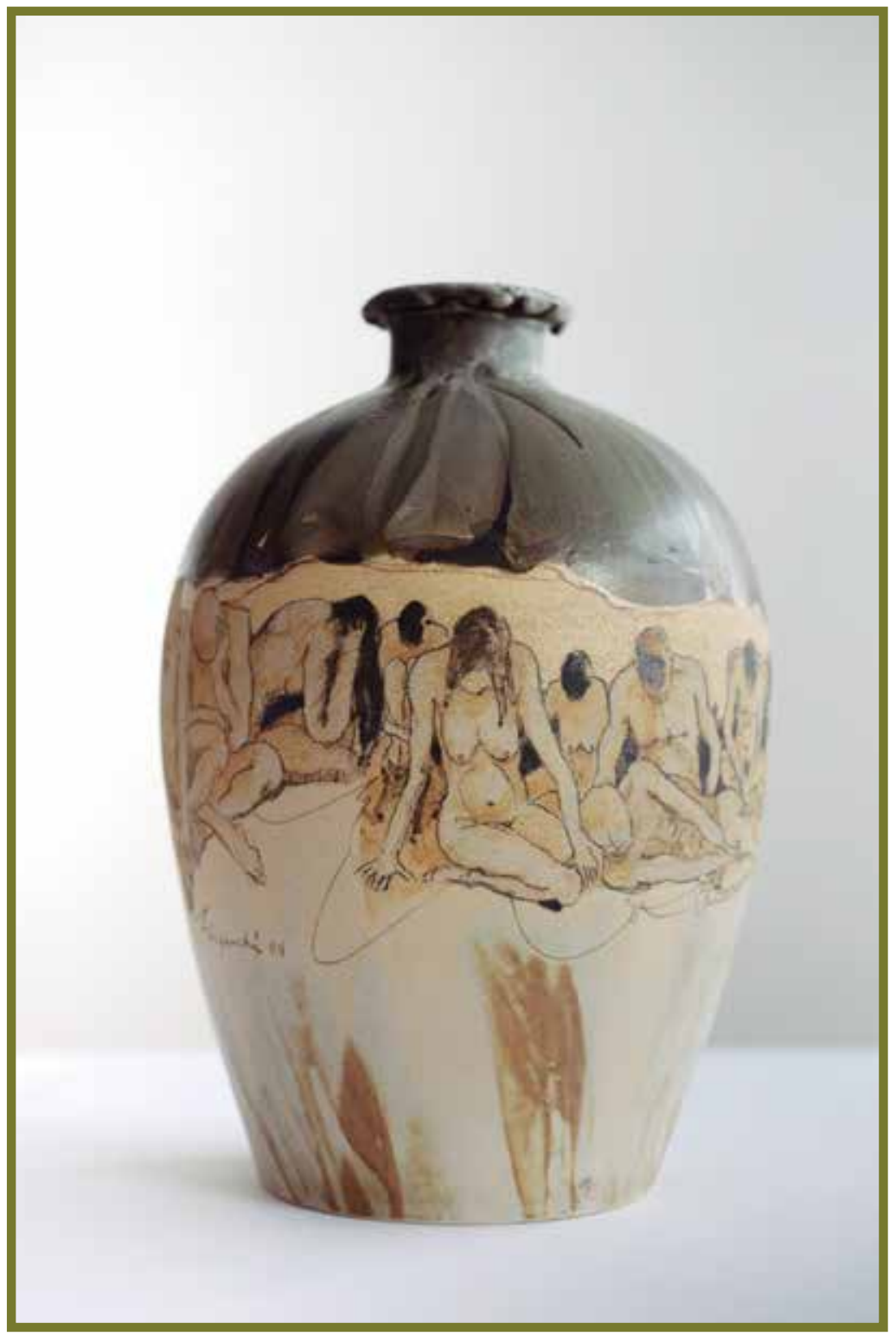

Meditar, 2008. Cerámica gres, $40 \times 30 \times 30 \mathrm{~cm}$.

Destacado artista plástico nikkei, Oswaldo Higuchi (Perú, 1948) 


\section{RESUMEN}

El artículo desarrolla el Criminal Compliance a partir de la realidad que presenta el Perú respecto a los programas de cumplimiento; esto es como respuesta a los escándalos en el mundo corporativo; pero también destaca los beneficios de su implementación en el desarrollo de las pequeñas y microempresas.

Palabras clave: compliance, microempresa, ética, corrupción.

\section{ABSTRACT}

The article addresses the Criminal Compliance from the standpoint of the Peruvian reality regarding compliance programs; this is a response to the scandals from the corporate world; but it also highlights the benefits of its implementation within the development of micro businesses and small businesses.

Key words: compliance, small businesses, micro businesses, ethics, corruption. 


\section{INTRODUCCIÓN}

En estos días, a casi 20 años de iniciado el siglo XXI, es "normal" hablar de globalización y "natural" ser partícipe de ella; pues, el ciudadano de hoy es el ciudadano del mundo; el mercado de hoy traspasa fronteras, es una época en la que, los avances tecnológicos, la gestión por proyectos, las normas ISO, los sistemas integrados, entre otros, no solo alcanza a todos, sino que está en constante cambio; frente a ello, las personas, las grandes y medianas empresas, así como las microempresas tienen que adaptarse aquellos cambios para permanecer en el mercado. Según el Instituto Nacional de Estadística e Informática (INEI), el número de empresas constituidas en Perú creció un 8,4\% en el año 2017, siendo un total avance a comparación del año 2016 que alcanzó un 3,98 \%. ${ }^{1}$

Por otro lado, esta inserción natural de las empresas en la era de la globalización también trae consigo malas prácticas sobre todo de las grandes corporaciones que con actos de corrupción como una manera ilícita de alcanzar no solo mayores beneficios económicos sino incluso también de poder, afectan la sociedad; el Perú no escapa de tales prácticas; se está viviendo una crisis de valores éticos, que se refleja en el mal uso de la ley para favorecer intereses personales y empresariales; $y$ lo peor es que el ciudadano de a pie acepta tales prácticas como lo normal, "sin darse cuenta" ni diferenciar lo correcto de lo incorrecto, por ejemplo: el conocido pago de coimas en las compras públicas, que por un lado afecta al Estado que gasta más recursos en pocos servicios públicos, a la misma empresa que al cierre del ejercicio fiscal declara mayor renta y obviamente al ciudadano de a pie que paga sus impuestos pero no los ve reflejado en un mejor servicio público. Por ello "el Perú ha sido víctima del fenómeno de la criminalidad empresarial (...) por las actividades de empresas nacionales y multinacionales que, en busca del máximo lucro, incurren en incorrecciones en el dominio tanto económico como fiscal". ${ }^{2}$

1 El Comercio, "El número de empresas en el Perú creció 8,4 \% en el 2017”, El Comercio, 01 de marzo de 2018, S. P.

2 José Hurtado Pozo, Compendio de derecho penal económico. Parte general (Lima: Fondo Editorial de la Pontificia Universidad Católica del Perú, 2015). 
Seńala Hurtado Pozo, citando a Gracia Martín, que la criminalidad de empresa vendría a ser la suma de los delitos de contenido económico que se cometen a través o teniendo como medio la actividad empresarial, debiendo diferenciarse, entonces, cuándo se actúa valiéndose de la estructura empresarial y cuándo alguno o algunos colaboradores de la empresa causan un dańo a la empresa misma o a otros colaboradores, ya que entonces estaríamos hablando de lo que la doctrina alemana ha denominado criminalidad en la empresa. ${ }^{3}$

Frente a esta situación, ha sido necesario que surjan nuevos modelos jurídicos como el de la responsabilidad de la persona jurídica, que implica la intervención del Estado mediante regulación en el mayor control de las actividades empresariales, encargando al empresario a hacerse cargo de la adopción de mecanismos que le permitan un desempeńo más diligente. Se hace referencia al sistema de cumplimiento normativo, conocido también como el compliance; ahora bien, ¿esta regulación afecta igual a todas las empresas, sean grandes, pequeñas o medianas?, ¿'todas las empresas podrán implementar un modelo de compliance?

En la literatura científica sobre el Criminal Compliance en el Perú, se ha encontrado el artículo de Clavijo Clave, que señala que "en la actualidad, para controlar y prevenir estos nuevos riesgos que se generan como consecuencia de la actividad del sector empresarial, se ha creado el Compliance Program o Programa de Cumplimiento Normativo, el cual constituye un mecanismo de autorregulación de las empresas para prevenir y/o evitar la comisión de infracciones legales (...)" ${ }^{4}$ En su análisis sobre el origen y contenido del compliance, agrega que además de evitar la comisión de infracciones normativas, deberá tenerse en cuenta "la buena imagen que pueda tener en el mercado frente a accionistas y clientes (...)”.

Por su parte, García Cavero seńala que "cuando se comete un delito desde la actividad de una empresa, las reglas generales de la imputación penal deben tener en consideración las particularidades propias del sector empresarial"; ${ }^{5}$ es decir que si la empresa ha implementado un sistema de compliance idóneo, tendría que tenerse en cuenta a la hora de proceder con la imputación penal; y si no lo hubiera implementado o no ha sido idóneo, se deberá evaluar si la responsabilidad penal alcanza a los responsables de su implementación. En esta parte es necesario hacer mención que como característica de la empresa se debe considerar también que las hay micro, pequeñas y grandes; por lo cual, no todas estarían en las mismas condiciones de realizar una infracción o de evitarlo mediante la implementación del compliance.

\footnotetext{
Ibidem, 196-197.

4 Camilo Clavijo Jave, Criminal Compliance en el derecho penal peruano, (Lima: Derecho PUCP, 2014), 625-647.

5 Percy García Cavero, Criminal compliance: en especial compliance anticorrupción y antilavado de activos (Lima: Instituto Pacífico, 2017): 113.
} 
Desde la teoría del delito, García Cavero distingue “dos ámbitos generales de la imputación penal en el marco de las actividades empresariales: el ámbito de la responsabilidad penal de la empresa misma y el que se corresponde con la imputación de la responsabilidad penal a sus miembros individuales".

De acuerdo con lo expuesto, el objetivo del artículo es abordar el criminal compliance como mecanismo no solo de cumplimiento normativo para evitar la posible sanción penal sino denotar su importancia para el desarrollo de la pequeña y mediana empresa.

\section{LA FUNCIÓN DE LA EMPRESA}

Se entiende por "empresa toda organización de capital y trabajo destinada a la producción o mediación de bienes o servicios para el mercado; y debido a que la empresa constituye un marco con características propias, es a su vez asidero de fenómenos criminales específicos"; 6 definición enfocada en las grandes corporaciones que de alguna manera dieron origen a hechos de sobornos y corrupción.

No obstante, si bien, dentro de una empresa, en el día a día, se desarrolla una gran cantidad de tareas, que de manera general se consideran unas funciones básicas, como son social, administrativa, comercial, técnica y financiera ${ }^{7}$, las cuales son de suma importancia para el logro de sus objetivos no solo económicos, sino también de carácter social, en tanto que una empresa, independientemente de los fines de lucro que normalmente tenga, tiene fines de carácter social, en tanto que el desarrollo de sus actividades están orientadas a brindar un producto o servicio a la sociedad; siendo necesario que para su propio desarrollo, actúe de forma ética, entendiendo la ética como aquel tipo de saber que pretende encaminar el quehacer humano en un sentido racional.

Las relaciones entre seres humanos y de estos con el mundo se basan en valores o antivalores; la ética busca un conocimiento objetivo y fundamentado de tales relaciones.

Una organización funciona de forma correcta cuando existe una sincronía de los elementos divididos en áreas que se establecen anteriormente. Si existe un fallo en alguna de ellas, sus consecuencias se reflejarán en el resto de las categorías y la organización no podrá funcionar de forma correcta. Todos los integrantes de la empresa tienen cierta participación en todas las áreas establecidas, a pesar de su empleo específico, cada parte de la organización es tan importante como esta, vista como una totalidad. ${ }^{8}$

6 Yasmina Riega-Virú, “Aproximación a la etiología del derecho penal económico en el marco empresarial peruano”, Revista Jurídica (2013).

7 Diario Economía, “¿Cuáles son las funciones básicas de una empresa?”, Diarioeconomía, 30 de octubre de 2015, acceso el 14 de agosto de 2019, https://okdiario.com/economia/funciones-basicas-empresa-15556

8 Henry Fayol, "Utel.edu.mx", acceso el 14 de agosto de 2019, https://www.utel.edu.mx/blog/10-consejos-para/las-funciones-basicas-de-la-empresa-segun-henry-fayol-2/. 
Respecto a la micro y pequeña empresa se hace referencia a lo señalado por Riega Virú:?

[...] en el caso peruano, por lo general, las empresas no son de la magnitud de aquellas que están siendo analizadas como sujetos activos de la criminalidad económica, sino que, por el contrario, en su mayoría, el empresariado peruano está compuesto por las llamadas micro y pequeñas empresas (mypes); las cuales son las que tienen importantes repercusiones económicas y sociales para el proceso de desarrollo del Perú. Baste decir, que constituyen el $98 \%$ de todas las empresas en dicho país; generan el $75 \%$ de la PEA, y producen riquezas en más de $45 \%$ de PBI. Las pymes constituyen la mejor alternativa para hacer frente al desempleo nacional, especialmente al alarmante desempleo juvenil.

Situación que se mantiene actualmente; pues, según la Cámara de Comercio de Lima, "las pequeñas y medianas empresas aportan significativamente al PBI y dan empleo al $75 \%$ de la PEA. ${ }^{10}$

\section{LA INSTITUCIÓN DEL COMPLIANCE}

El compliance surgió como una necesidad de cambio, producto de la creación de empresas, de un mayor desarrollo normativo a efectos de brindar la debida seguridad jurídica. Tal como vimos anteriormente, vivimos en sociedades regidas por un número cada vez mayor de leyes, códigos y normas. Un entramado legal que no solo afecta a los ciudadanos, sino también a las empresas: en la medida en que estas operan e interactúan con la sociedad, también tienen que ajustarse a una normativa que, en definitiva, está orientada a posibilitar la convivencia y garantizar el funcionamiento del sistema. ${ }^{11}$

Es decir, la figura del compliance surgió para asegurar que la empresa se ajuste y cumpla con el ordenamiento jurídico; pero también para asegurarse y verificar que en la empresa se cumpla con sus propias normas internas. Lo que representa un esfuerzo por devolver la confianza en el sistema, y sobre todo en las compañías que a lo largo de los años habían adquirido una mala reputación embestida producto de las acciones de comisión de actos delictivos.

El término es utilizado por instituciones tanto públicas como privadas, a fin de obtener una reputación, y aunque la misma está ligada a intereses de mercado y deber ser de carácter empresarial, se utiliza para no recaer en acciones ni hechos que a la larga puedan perjudicar el

9 Riega-Virú, “Aproximación...”, 148.

10 Cámara de Comercio de Lima, "XIII Expo Pyme 2018: ¿Cómo llegar a ser una pyme de clase mundial? Desafíos, oportunidades y retos", acceso el 15 de agosto de 2019,

https://www.camaralima.org.pe/principal/noticias/noticia/pymes-emplean-al-75-de-la-pea/1117

11 Marta Remacha, “Compliance, ética y RSC”, Cuaderno N³1, julio del 2016 de la Cátedra "la Caixa” de Responsabilidad Social de la Empresa y Gobierno Corporativo, 5-21, acceso el 10 de octubre de 2018, https://media.iese.edu/research/ pdfs/ST-0411.pdf 
nombre o el denominado goodwill ${ }^{12}$ de una empresa. Asimismo, es de recordar que la palabra "compliance" responde nada más que a un deber de cumplimiento al cual se someten en la actualidad gran sector innovador de las empresas, siendo así ¿por qué implantar este sistema? Pues, en teoría lo novedoso siempre es difícil de adquirir; sin embargo, los altos niveles de informalidad, ilegalidad e incluso corrupción han orillado a las grandes empresas, grupos empresariales y corporaciones a adherirse a este mecanismo, ya que tales actos atentaban contra ese activo intangible del cual goza una empresa y ello las ligaba a responder penalmente frente a determinadas situaciones.

Para Vila \& Uribe, "El tratamiento del compliance y su aplicación en el ámbito del Derecho Penal resulta cuestión novedosa en los diversos países de nuestra región, afiliados tradicionalmente al sistema de codificaciones y que han recusado continuamente la idea de la responsabilidad penal de las personas jurídicas. Hoy en día esa realidad ha cambiado y ha provocado toda una innovación de contenidos y de visiones". ${ }^{13}$ Lo mencionado por los mismos, hace referencia a la relación de este concepto corporativo al ámbito del derecho penal, donde en base a escalas de calificaciones y deberes éticos se busca someter a las empresas elevando sus niveles y busca reducir en la medida en que fuere posible la responsabilidad penal que se pudiera derivar de la realización de ilícitos, o por lo menos tener un mayor control de prevención en el marco funcional y gestacional de la empresa.

Por su parte, Coca Vila señala que "por compliance hay que entender aquel conjunto de medidas tendentes a garantizar que todos y cada uno de los miembros de una empresa, desde el presidente del consejo de administración hasta el último empleado, cumplan con los mandatos y las prohibiciones jurídico-penales, y a que, en caso de infracción, sea posible su descubrimiento y adecuada sanción”. ${ }^{14}$

12 El agio por expectativa de rentabilidad futura (goodwill) es el valor extra atribuido a una empresa en virtud, por ejemplo, de su reputación, posición competitiva y lealtad de los clientes. El goodwill representa los beneficios económicos futuros resultantes de los activos adquiridos, en una operación de combinación de negocios, los cuales no son individualmente identificados y separadamente reconocidos. Se esclarece que el goodwill pasa a existir después de todas las tentativas de mensuración objetiva de todo lo que más está siendo adquirido. Diferentemente de la práctica contable anterior en que, comúnmente, toda la diferencia entre el valor pagado y el valor contable era clasificada como ese tipo de agio. Por tanto, conceptualmente, el goodwill y el agio por diferencia de mercado de los activos líquidos son acepciones distintas. El goodwill es apurado por la diferencia entre el valor de adquisición de la inversión y el valor justo de los activos líquidos de la inversión, siendo contabilizado por su valor de coste líquido de las pérdidas acumuladas por impairment. El agio por diferencia de valor de mercado de los activos líquidos corresponde a la diferencia entre el valor justo y el valor contable de los activos líquidos de la inversión y es amortizado conforme la realización de esos activos.

13 Coca Vila \& Uribe Manrique, “Compliance y responsabilidad penal de las personas jurídicas: perspectivas comparadas EE.UU, Espańa, Italia, México, Argentina, Colombia, Perú y Ecuador”, Gaceta Penal \& Procesal Penal: Información Especializada para Abogados, Jueces y Fiscales, tomo 104 (2018): 245.

14 Ivó Coca Vila, “¿Programas de cumplimiento como forma de autorregulación regulada?”. En Criminalidad de empresa y compliance, de Jesús-María Silva Sánchez y Raquel Montaner Fernández (Barcelona: Atelier Libros Jurídicos, 2013 ), 43. 
Como es de verse, la implementación de un programa de cumplimiento, permitirá de manera más sencilla encontrar la responsabilidad penal de quienes infringen la normativa, tanto de la empresa como la contenida en el ordenamiento jurídico; beneficiando a la empresa en sí misma y al propio Estado.

Por otro lado, es de considerarse que el derecho penal lo que busca es regular aquellas conductas que vayan en contra del orden público o que de encajar en tales supuestos se hayan previsto las sanciones necesarias para que tal conducta y el correspondiente daño producido no queden impunes. De allí, que hasta el día de hoy cuando se habla de la comisión de delitos aún se hace referencia a supuestos de carácter individual donde los sujetos materia de imputación son las personas jurídicas en sí mismas.

En ese sentido, el derecho penal como última ratio en el ámbito sancionador busca imponer la medida correctiva necesaria a los sujetos que a pesar de haberse encontrado bajo la previsión legislativa de la norma no cumplieron con lo establecido. Ligado al compliance se tiene que ambos buscan el cumplimiento normativo y mejor desenvolvimiento en el campo en el que buscan desarrollarse. A decir de ello, según Huailla:

[...] el criminal compliance comprende la totalidad de las medidas, necesarias ex ante y ex post no contrarias al derecho penal, normativas, institucionales y técnicas de una organización que están dirigidas a sus miembros, al Estado o al público, ya sea para a) minimizar preventivamente el riesgo de que mediante la organización se cometa un delito de derecho penal económico relacionado con la organización, contra el derecho interno o extranjero, o que la correspondiente sospecha inicial de dicha comisión llegue a originarse; o b) represivamente, aumentar las posibilidades de influenciar positivamente, en consenso con la autoridad materia de persecución penal en sentido amplio y, con ello, finalmente, c) aumentar el valor de la empresa. ${ }^{15}$

Al respecto, el criminal compliance como factor preventivo y especializado en razón de un tratamiento antes, durante e incluso después de la realización del hecho delictivo de implicancia económico empresarial donde se afecte el mercado e incluso la economía nacional e internacional relacionado con la persecución que pueda responderse por la no implementación de este sistema; es necesario no solo para las grandes corporaciones sino también para las micro y pequeńas empresas, pues como bien señala Coca Vila: “... es conditio sine qua non el que en la empresa reine una cultura de cumplimiento (compliance culture), eso es, tanto trabajadores como directivos deben interiorizar la necesidad de que todo lo que sucede en la empresa, de puertas para afuera y de puertas para adentro, sea respetuoso para con el ordenamiento jurídico $[\ldots] "$.

15 Ana Cecilia Hurtado Huailla, "Responsabilidad penal de la persona jurídica y criminal compliance: ¿̇una opción político-criminal?”, Gaceta Penal \& Procesal Penal: Información Especializada para Abogados, Jueces y Fiscales, tomo 77 (2015): 88. 
En suma, se podrá hablar de compliance en el derecho penal económico cuando se busquen llegar a estándares reputacionales más altos de los que se pretende, en tanto que van más allá de la autorregulación para cumplir con la ley; sino que será una práctica el que cada uno de los miembros de la empresa adecúe su actuar conforme a derecho, porque así lo han interiorizado.

\section{REGULACIÓN DEL COMPLIANCE EN EL PERÚ}

Previo a abordar la regulación, se considera necesario hacer referencia a la Organización para la Cooperación y el Desarrollo Económico (OCDE), cuya una de sus funciones es la incorporación de países en razón a la implementación de buenas prácticas de carácter empresarial y social. "Fundada en 1961, la Organización para la Cooperación y el Desarrollo Económicos (OCDE) agrupa a 36 países miembros y su misión es promover políticas que mejoren el bienestar económico y social de las personas alrededor del mundo". ${ }^{16}$

Es de mencionar que la pertenencia de un país a la OCDE aumenta su reputación debido a que formaría parte de un grupo de países que constituyen aproximadamente el $70 \%$ u 80 $\%$ del PBI mundial, es decir, gran parte de la economía, ingresos e importaciones que realiza el mundo; y a la par de ello su movimiento de capitales está referido a las actividades de comercio, etc. Ello desde un punto de vista económico; sin embargo en esta organización no solo se tratan temas de carácter económico con países que evidentemente superan el capital mundial, sino que también se regulan temas de políticas públicas, ante las cuales se llega a un consenso y consecuente aprobación a efectos de fomentar el diálogo entre sectores presentando las debidas estadísticas y diversos análisis sobre los efectos que pudieren tener las nuevas políticas que se deseen implementar en el campo económico y social.

Los fines de la OCDE son, según el Ministerio de Asuntos Exteriores, Unión Europea y Cooperación, ayudar a la mejora de las políticas públicas de un lugar centrando su trabajo “(...) en el análisis del desarrollo económico y social, así como todas las políticas sectoriales que influyen en él. De ahí, que su ámbito de actividad abarque no solo el estudio y seguimiento de la situación económica y de las políticas económicas que se aplican en los diferentes países, sino también las cuestiones sociales, medioambientales, de buen gobierno de las instituciones, energía, educación, economía de la salud, actividades industriales y de servicios, comercio, ayuda al desarrollo, etc.”. El análisis de carácter económico que se realiza va derivado de las expectativas de un Gobierno que sea equitativo con lo que percibe; no bastará entonces que se tengan buenas políticas de diversos temas pero que enfocadas a la realidad las mismas no tengan razón de ser y se encuentren guiadas a ser parte de lo que debería constituir mas no de lo que es.

16 OCDE, Organización para la Cooperación y el Desarrollo Económicos, acceso el 10 de agosto de 2018, https://www.oecd.org/centrodemexico/laocde/ 
El Perú viene trabajando arduamente para su incorporación en la OCDE, sin embargo, "el análisis del Estudio multidimensional de la OCDE para el Perú muestra que para dar respuesta a los obstáculos al desarrollo que todavía enfrenta el país, es necesaria la coordinación y la coherencia de las políticas entre varias dimensiones sociales, económicas e institucionales". ${ }^{17}$

Como es conocido por todos, el Perú como nación está pasando por un mal momento político. Los niveles de corrupción hacen que el ciudadano desconfíe no solo de las actividades que realiza el trabajador de la empresa sino también de los propios socios, que en teoría siempre buscan el bien de su corporación; sin embargo, se ha encontrado que en algunos casos se esconden finalidades ajenas al marco legal. Entendiéndose la corrupción como:

[...] un problema estructural que afecta a la sociedad, el sistema económico-financiero y la legitimidad del Gobierno. Este fenómeno se expresa de distintas maneras y a través de diferentes actores, que incluso no conforman el Sector Público. En ese sentido, si bien las reformas legislativas no solucionan de manera eficaz el problema de la corrupción, es necesario incorporar en nuestro texto punitivo una fórmula legal que sancione la corrupción entre particulares. ${ }^{18}$

Es decir, se busca en teoría incorporar dentro del propio marco legal resolver este problema para no solo sancionar a los particulares en el ámbito del sector público sino también sancionarlos en el marco del sector privado; pues, "La corrupción se materializa con el uso indebido del poder. Es imperioso un mayor control de los particulares que ejercen funciones públicas en forma permanente o transitoria, que presten servicios públicos a cargo del Estado o administren sus recursos"(Flores, Mecanismos y Lucha contra la Corrupción desde el Estado y la Sociedad: hacia un modelo programático para el caso peruano 2018, 37).

Bajo este marco, al revisar el Código Penal peruano, se encuentra que el legislador consideró que la persona jurídica no puede responder por la comisión de delitos, pero sí se le puede imponer las consecuencias accesorias establecidas en el artículo $105^{\circ}$ de la norma acotada, como son suspensión de actividades, disolución y liquidación, "si su organización es peligrosa en términos de favorecer o encubrir hechos delictivos de sus miembros individuales". ${ }^{19}$ Sin embargo, la regulación de la responsabilidad de la persona jurídica ha sido discutida y propuesta, en el orden siguiente:

17 OCDE, Estudio multidimensional del Perú, volumen 1, Evaluación inicial. Mensajes principales, https://www.oecd.org/ dev/MDCR\%20PERU\%20Principales\%20mensages_FINAL.pdf

18 Daniel Pisfil Flores, "Mecanismos y lucha contra la corrupción desde el Estado y la sociedad: hacia un modelo programático para el caso peruano", Gaceta Penal \& Procesal Penal: Información Especializada para Abogados, Jueces y Fiscales, tomo 104 (2018): 36.

19 Percy García Cavero, Criminal compliance: en especial compliance anticorrupción y antilavado de activos (Lima: Instituto Pacífico, 2017). 


\section{Proyecto de Ley $\mathrm{N}^{\circ} 3851 / 2014-\mathrm{CR}$ :}

Propuesto por la Comisión de Justicia y Derechos Humanos del Congreso de la República del congresista Yehude Simón Munaro y otros, que tiene como asunto modificar el artículo 107 del Código Penal cuyo objetivo es ponerle un freno, todo ello referente a un mayor control en la lucha contra la corrupción.

\section{Proyecto de Ley No 4054/2014:}

Respecto de tal proyecto de ley, se ha previsto un dictamen que propone una regulación adicional de la regulación de la responsabilidad autónoma de las personas jurídicas en delitos de corrupción.

\section{Ley $N^{\circ} 30424$ :}

A decir de Ramírez:

La Ley $\mathrm{N}^{\circ} 30424$, modificada por el D. Leg. 1352, exige la implementación de un programa de cumplimiento (compliance) por parte de todas las personas jurídicas del país a fin o evitar la comisión de los delitos de cohecho activo genérico y específico, cohecho activo transnacional, lavado de activos, minería ilegal o terrorismo por parte de los miembros de la empresa. ${ }^{20}$

Con ello se buscaba presentar una modificación a la denominación de la Ley $\mathrm{N}^{\circ} 30424$, ley que regula la responsabilidad administrativa de las personas jurídicas por el delito de cohecho activo transnacional. Por lo que "el marco legal tiene dos aspectos sustanciales: (i) las sanciones que pueden ir desde una multa hasta el cierre del negocio y (ii) el modelo de prevención que, si se implementa y aplica correctamente, puede salvar a la compañía”. ${ }^{21}$

Siguiendo la misma línea, con acotada disposición se esclarece aún más el tratamiento legislativo que puede tener la persona jurídica respecto de las responsabilidades que se le imputan, y aunque en este caso se hace sobre los órganos administrativos de referido sujeto de derechos, que poco a poco se está planteando un tratamiento más adecuado dejando de lado la percepción de ficción legal en algunas oportunidades, es decir, "la norma, que pone al Perú en la vía de los países que castigan la criminalidad ligada a la corrupción cometida por personas jurídicas, relevante ahora con el destape de Lava Jato y el club de la construcción, tiene, sin embargo, algunos cuestionamientos por parte de los expertos" ${ }^{22}$

\footnotetext{
20 Mercedes Ramírez, “Compliance, programa exigido a empresas para evitar sanciones”, Perú21, acceso el 28 de enero de 2018, s.p.

21 Ibidem.

22 Ibidem.
} 
Ahora bien, así como se establecen supuestos de responsabilidad, también es cierto que se están previendo aquello que resalta respecto de las ventajas de tales incorporaciones legislativas, ya que "lo más importante de esta nueva legislación es que ahora las empresas pueden ser responsables por los actos de sus subordinados o empleados representantes cuando antes esto no existía", ${ }^{23}$ por lo que así como también se han incorporado responsabilidades nuevas e incluso nuevos sujetos de imputación, también es cierto que para ciertos casos se va a eximir de responsabilidad cuando no se encaje en determinado supuesto de hecho contenido en la norma y que va contra de lo establecido por el legislador solo por faltar uno de los requisitos para ser tipificado. Los delitos a los que se hace referencia en la Ley $N^{\circ} 30424$ son:

\section{a. Lavado de activos}

El lavado de activos se encuentra regulado en el Perú encerrando una variedad de supuestos, los cuales se encuentran entre los artículos 1 y 2 , y sobre sus agravantes de su artículo 3 en adelante, en su ley especial Ley Penal Contra el Lavado de Activos - Ley N ${ }^{\circ}$ 27765; ahora bien, respecto a la conceptualización que se le da a este delito se obtiene lo siguiente: "El lavado de activos supone un proceso mediante el cual se pretende disfrutar de los beneficios económicos de un delito previo a través del ocultamiento de su origen ilícito". ${ }^{24}$

Respecto de ello, Sosa menciona que "la complejidad misma de del lavado de activos, que busca justamente sortear toda actividad persecutoria del delito; su indudable vinculación con la criminalidad organizada; actos de corrupción; quizás estas pueden ser solamente algunas de las razones por las cuales, tras una larga investigación o juzgamiento". ${ }^{25}$ Por lo que actos como los que se realizan de parte de los sujetos materia de imputación no podrían realizarlos solos, y en la mayoría de ocasiones se está hablando de sujetos que se agruparon con otros, a los que se les denomina organizaciones criminales.

Continúa Sosa apreciando lo siguiente:

Gálvez Villegas y Delgado Tovar consideran que cada uno de estos delitos presenta su propia identidad, lo que permite diferenciarlos debidamente atendiendo a algunos aspectos tales como el bien jurídico tutelado, el objeto de la acción, la presencia de elementos subjetivos distintos del dolo, entre otros. Así, estos autores entienden que el lavado de activos tiene como objeto de protección el sistema económico y la administración de justicia. ${ }^{26}$

23 Giovani Alarcón, “¿Por qué las empresas deberían tener un programa de compliance?”, Gestión, acceso el 23 enero de enero de 2018, s.p.

24 Eduardo Oré Sosa, "Delitos económicos y contra la Administración pública”, Gaceta Penal \& Procesal Penal: Información Especializada para Abogados y Jueces, tomo 46 (2013): 166.

${ }^{25}$ Ibidem.

26 Ibidem, 169. 
De ello se deriva que el delito de lavado de activos afecta no solo un bien jurídico protegido y dirigido hacia un sujeto, sino que en ocasiones se encuentra ligado al mal desarrollo del mercado y de las relaciones empresariales, sobre como esconder el dinero que de por sí proviene de otras actividades que no se encuentran admitidas por ley y que por su parte generan un beneficio ya que se hacen pasar como lícitas.

\section{b. Cohecho}

Según Bocanegra, "El delito de cohecho pasivo se encuentra considerado como el tipo penal insigne que representa el soborno cotidiano realizado entre funcionarios públicos y particulares o contrato sinalagmático celebrado con el fin de efectivizar la compra-venta de la función pública". ${ }^{27}$ Coloquialmente hablando, se tiene que el cohecho lo constituyen todas aquellas actividades a las que se les denomina soborno y que afectan el debido desarrollo de la función pública.

Continúa el mismo autor diciendo lo siguiente: "En nuestro ordenamiento jurídico se ha proscrito la conducta tanto del funcionario que acepta o solicita el pago por la venta de la función pública como del sujeto particular que compra o recibe el ofrecimiento del funcionario. La primera es el delito de cohecho pasivo y la segunda el de cohecho activo genérico". ${ }^{28}$ Es decir que con tal presupuesto se está abusando de la función que se tiene como parte del sector público, recibiendo ingresos de parte de terceros, e incluso el ofrecimiento de tales ya configura tal supuesto normativo.

\section{CONSIDERACIONES SOBRE LA IMPLEMENTACIÓN DEL COMPLIANCE EN LA EMPRESA}

Teniendo en cuenta los puntos desarrollados precedentemente, se puede advertir, pues, que el criminal compliance se inserta dentro de la conformación de una empresa con el fin de poder generar la confianza no solo internamente sino que esta se irradie hacia el exterior, a efectos de poder evidenciar el cumplimiento no solo de sus políticas internas que aseguren la finalidad de la misma, sino que además permita evidenciar el cumplimiento del marco normativo específico frente a los órganos responsables de su aplicación, en este caso las autoridades judiciales.

El compliance, más allá de ser una imposición, esto es, una autorregulación regulada debe ser vista como una oportunidad de desarrollo empresarial; en tanto que, en un am-

\footnotetext{
27 Rocío Bobadilla Bocanegra, "La dificultad probatoria del delito de cohecho pasivo: hacia la redacción del tipo penal basado en la factibilidad heurística y probática”, Gaceta Penal \& Procesal Penal: Información Especializada para Abogados, Jueces y Fiscales, tomo 104 (2018): 48.

28 Ibidem, 53.
} 
biente de ética resquebrajada, la implementación de esta institución permitirá recobrar los valores con el actuar diligente de cada uno de sus miembros, creando o mejorando la cultura organizacional en base a un desempeńo dentro del cumplimiento del derecho. Además, el desempeño de los miembros de la empresa basado en la ética y respeto por la norma evitará reprocesos en el desarrollo de sus actividades, lo cual se verá reflejado en la mejor satisfacción de sus clientes, mejorando su imagen corporativa y, con ello, mejorando sus ratios económicos.

En ese sentido, la intención de la publicación es hacer notar que, si bien la norma no obliga a la implementación de un sistema de cumplimiento normativo a todas las empresas, lo cierto es que es recomendable su implementación en la medida de lo posible en todas ellas, más aún, en las pequeñas y medianas empresas que independientemente de permitirles prevenir la comisión de algún delito o reducir una sanción en el supuesto de su comisión les garantizaría un actuar diligente y ordenado, con miras a un mejor desarrollo empresarial. Puesto que el compliance involucra un mecanismo de prevención y búsqueda de las buenas prácticas en el marco de la legalidad, dotando de una estrategia que permitirá la identificación de los riesgos de comisión de delitos, para prevenirlos, hacerles seguimiento, o detectar la comisión de algún delito, en cuyo caso tendrá que ser denunciado.

De manera general, la implementación de un programa de cumplimiento traerá como consecuencia que los responsables de las áreas competentes lleven adelante la generación y ejecución de contratos y además cumplan de manera eficaz con los intereses de la empresa, orientando la finalidad de la persona jurídica ya no solo en pro de sí misma, sino también en pro de la sociedad, a través de la responsabilidad social a la vista de sus consumidores directos y de la propia sociedad.

Pero la responsabilidad social no responde solo a la percepción positiva que se pretende obtener de la sociedad civil como empresa, sino que el Estado también ha visto la necesidad en el afán de poder dar cumplimiento a las competencias propias de los órganos encargados poder contar con aquellos elementos que le permitan determinar el cumplimiento de las normas legales, trasladando la carga de la prueba, su falta de responsabilidad a través de una estrategia adecuada y eficaz a las personas jurídicas.

Desde un punto de vista estratégico, el Estado ha introducido al órgano con la función de compliance en las entrañas de los entes corporativos como si de un "caballo de Troya" se tratase. El método utilizado no ha sido a través de la aprobación de una norma general y ordinaria que obligue taxativamente a que cada persona jurídica cuente con un órgano autónomo encargado de velar por el cumplimiento de los modelos de prevención de delitos, sino que ha acudido a una vía mucho más sutil: posibilitar que el ente corporativo quede dispensado de responsabilidad penal ante la comisión de un delito en su seno cuando, entre otros aspectos, se haya implementado un modelo de organización y gestión para la 
prevención de delitos o compliance program penal eficaz, dotándose de este órgano con unos poderes autónomos que le permitan velar por su cumplimiento.(...). ${ }^{29}$

La norma especializada tiende a ser aplicada conforme se encuentra establecido, ello a mérito del principio de legalidad. En ese sentido, su aplicación espacial y temporal recae directamente a la empresa desde el punto de vista integral no realizando distinción alguna; sin embargo, los procesos que se generan en las actividades propias de su constitución determinarán los procesos que deberán de implementarse para probar el cumplimiento del criminal compliance. Estas condiciones que se presentan deberán de ser tomadas en cuenta por el Ministerio Público cuando determine la viabilidad de apertura de investigación.

\section{CONCLUSIONES}

1. La era de la globalización trajo consigo malas prácticas, las que se evidenciaron a través de los actos de corrupción y de manera ilícita de las grandes corporaciones a fin de alcanzar los mayores beneficios económicos y también el poder, con ello afectando a la sociedad; viéndose involucrado el Perú en estas prácticas; haciendo mal uso de la ley a fin de favorecer sus intereses personales y empresariales. Motivo por el cual el Estado ha adoptado nuevos modelos jurídicos como el de la responsabilidad de la persona jurídica; que implica la intervención del órgano competente a través de la regulación y el mayor control de las actividades empresariales, trasladando la carga de la prueba al empresario, quien deberá de hacerse cargo de la adopción de mecanismos que le permitan un desempeño más diligente, a través del sistema de cumplimiento normativo, conocido también como el compliance.

2. En este momento, las empresas no solo realizan funciones básicas que permiten alcanzar sus fines utilitarios, sino que a estas funciones se ha incorporado el carácter social que se encuentra representado por la responsabilidad social que constituye a la fecha una labor que se encuentra equiparada en la misma intensidad que las labores económicas que la marcan dentro del mercado donde se desarrolla. Incorporándose a la ética empresarial desde la perspectiva de la creación de valores positivos, lo que se reflejará en las demás actividades de la empresa y en cómo lo percibe la sociedad.

3. La implementación del compliance puede ser aprovechado por las pequeñas y medianas empresas como mecanismo no solo para la prevención o detección de delitos que le permitan evitar una sanción, sino sobre todo para generar una cultura basada en el pleno cumplimiento del derecho que se verá reflejado en sus buenas prácticas hacia sus clientes, lo cual les traerá mejores réditos.

29 Rafael Aguilera Gordillo, "Régimen jurídico y fundamentación analítica de la responsabilidad penal de la persona jurídica y el compliance program" (2018),

https://dialnet.unirioja.es/servlet/tesis? codigo=150339 


\section{REFERENCIAS}

- Aguilera Gordillo, Rafael. "Régimen jurídico y fundamentación analítica de la responsabilidad penal de la persona jurídica y el compliance program” (2018).

https://dialnet.unirioja.es/servlet/tesis?codigo=150339

- Alarcón, Giovani. “¿Por qué las empresas deberían tener un programa de compliance?”. Gestión. Acceso el 23 enero de enero de 2018, s.p.

- Bobadilla Bocanegra, Rocío. "La dificultad probatoria del delito de cohecho pasivo: hacia la redacción del tipo penal basado en la factibilidad heurística y probática”. Gaceta Penal \& Procesal Penal: Información Especializada para Abogados, Jueces y Fiscales, tomo 104 (2018): 48-58.

- Cámara de Comercio de Lima. "XIII Expo Pyme 2018: ¿Cómo llegar a ser una pyme de clase mundial? Desafíos, oportunidades y retos”. Acceso el 15 de agosto de 2019.

https://www.camaralima.org.pe/principal/noticias/noticia/pymes-emplean-al-75-de-lapea/ 1117

- Clavijo Jave, Camilo. Criminal Compliance en el derecho penal peruano. Lima: Derecho PUCP, 2014.

- Coca Vila \& Uribe Manrique. "Compliance y responsabilidad penal de las personas jurídicas: perspectivas comparadas EE.UU, España, Italia, México, Argentina, Colombia, Perú y Ecuador”. Gaceta Penal \& Procesal Penal: Información Especializada para Abogados, Jueces y Fiscales. Tomo 104 (2018): 245-246.

- Coca Vila, Ivó. “¿Programas de cumplimiento como forma de autorregulación regulada?”. En Criminalidad de empresa y compliance, de Jesús-María Silva SaÁnchez y Raquel Montaner Fernández. Barcelona: Atelier Libros Jurídicos, 2013.

- Diario Economía. “Cuáles son las funciones básicas de una empresa?”. Diarioeconomía, 30 de octubre de 2015. Acceso el 14 de agosto de 2019.

https://okdiario.com/economia/funciones-basicas-empresa-15556

- El Comercio. "El número de empresas en el Perú creció 8,4 \% en el 2017”. El Comercio, 01 de marzo de 2018, S. P.

- Fayol, Henry. “Utel.edu.mx”. Acceso el 14 de agosto de 2019. https:/www.utel.edu.mx/blog/10-consejos-para/las-funciones-basicas-de-la-empresasegun-henry-fayol-2/

- García Cavero, Percy. Criminal Compliance. Lima: Instituto Pacífico, 2017. 
- García Cavero Percy. Criminal compliance: en especial compliance anticorrupción y antilavado de activos (Lima: Instituto Pacífico, 2017): 111-115.

- Hurtado Huailla, Ana Cecilia. "Responsabilidad penal de la persona jurídica y criminal compliance: ¿̇una opción político-criminal?”. Gaceta Penal \& Procesal Penal: Información Especializada para Abogados, Jueces y Fiscales, tomo 77 (2015): 81-96.

- Hurtado Pozo, José. Compendio de derecho penal económico. Parte general. Lima: Fondo Editorial de la Pontificia Universidad Católica del Perú, 2015.

- OCDE, Organización para la Cooperación y el Desarrollo Económicos. Acceso el 10 de agosto de 2018. https://www.oecd.org/centrodemexico/laocde/

- OCDE. Estudio multidimensional del Perú. Volumen 1. Evaluación inicial. Mensajes principales.

https://www.oecd.org/dev/MDCR\%20PERU\%20Principales\%20mensages_FINAL.pdf

- Oré Sosa, Eduardo. "Delitos económicos y contra la Administración pública". Gaceta Penal \& Procesal Penal: Información Especializada para Abogados y Jueces, tomo 46 (2013): 165-175.

- Pisfil Flores, Daniel. "Mecanismos y lucha contra la corrupción desde el Estado y la sociedad: hacia un modelo programático para el caso peruano". Gaceta Penal \& Procesal Penal: Información Especializada para Abogados, Jueces y Fiscales, tomo 104 (2018): 36-37.

- Mercedes Ramírez. "Compliance, programa exigido a empresas para evitar sanciones". Perú21. Acceso el 28 de enero de 2018, s.p.

- Remacha, Marta. "Compliance, ética y RSC”. Cuaderno N³1, julio del 2016 de la Cátedra "la Caixa" de Responsabilidad Social de la Empresa y Gobierno Corporativo, 5-21. Acceso el 10 de octubre de 2018. https://media.iese.edu/research/pdfs/ST-0411.pdf

- Riega-Virú, Yasmina. "Aproximación a la etiología del derecho penal económico en el marco empresarial peruano". Revista Jurídica (2013): 147-152. 